\title{
Anthropogenic disturbance on nursery function of estuarine areas for marine species
}

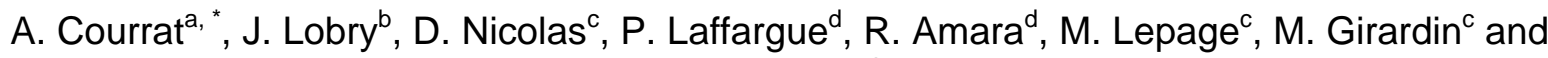 \\ O. Le Pape ${ }^{a}$
}

\author{
a Agrocampus Ouest, Laboratoire d'Ecologie Halieutique, UMR INRA ESE 985, 65 rue de St. Brieuc, CS 84215, \\ 35042 Rennes, France \\ ${ }^{\mathrm{b}}$ IFREMER, EMH, rue d'Ile d'Yeu, B.P. 21105, 44311 Nantes Cedex, France \\ c Cemagref (French Institute of Agricultural and Environmental Engineering Research), U.R. ECOSEMA, 50 \\ avenue de Verdun, Gazinet, 33612 Cestas Cedex, France \\ d Université du Littoral, UMR 8187 CNRS LOG, 32 avenue Foch, 62930 Wimereux, France
}

*: Corresponding author : A. Courrat, email address : acourrat@hotmail.com

\begin{abstract}
:
Estuaries serve as nursery grounds for many marine fish species. However increasing human activities within estuaries and surrounding areas lead to significant habitat loss for the juveniles and decrease the quality of the remaining habitats. This study is based on the data of 470 beam trawls from surveys that were conducted in 13 French estuaries for the purpose of the European Water Framework Directive. It aimed at testing the effects of anthropogenic disturbances on the nursery function of estuaries. With a multispecific approach based on ecological guilds, two fish metrics, abundance and species richness of Marine Juvenile migrant fishes, were used as proxies for the estuarine nursery function. Indices of heavy metal and organic contaminations were used to estimate anthropogenic disturbances impacting these estuaries. Fish metrics were described with statistical models that took into account: (a) sampling protocol, (b) estuarine features and (c) contamination. The results of these models showed that the fish metrics highly depend on the sampling protocol, and especially type of gear, depth and salinity, which highlights the necessity of considering such metrics at the sampling (trawl haul) scale. Densities and species richness of Marine Juvenile fishes appeared to be strongly and negatively correlated to contamination indices. These results are consistent with the hypothesis that human disturbances impact the nursery function of estuaries. Finally, the densities of Marine Juvenile migrant species appeared as a potential robust and useful fish indicator for the assessment of the ecological status of estuaries within the Water Framework Directive.
\end{abstract}

Keywords: essential fish habitat; nursery grounds; estuaries; fish indicators; anthropogenic disturbances; contamination 


\section{Introduction}

Estuaries are transitional zones of interaction between land and sea that present a very high level of productivity (Whittaker, 1975; Costanza et al., 1997). Because of some of their features, such as high salinity variations, low depths, muddy grounds, warm water, higher turbidity, the presence of various and rich habitats and high food availability, estuaries serve as nursery grounds for many marine fish species (Gibson, 1994; Able et al., 1999; Elliott and Dewailly, 1995; Riou et al., 2001; Jones et al., 2002; Meng et al., 2002; Peterson, 2003; Le Pape et al., 2003b; McLusky and Elliott, 2004; Elliott et al., 2007; Franco et al., 2008): juveniles aggregate in these areas where their fitness is enhanced through better feeding conditions, optimal growth, refuge opportunities and high connectivity with other habitats (Beck et al., 2001).

Nevertheless, estuarine zones are also characterized by a high level of human activity. More than $60 \%$ of the world's population lives within $60 \mathrm{~km}$ of the coast (Post and Lundin, 1996). The increasing urban and industrial development within estuarine areas leads to significant habitat losses (Coleman et al., 2008) for the juveniles. Furthermore, estuaries are the discharge point for all particles stemming from anthropogenic activities carried out within the drainage basin, including urban and industrial development as well as intensive agriculture. Therefore, in addition to increasing quantities of nutrients and organic materials, estuarine waters and sediments accumulate xenobiotics such as heavy metals and organic contaminants, which tends to degrade the quality of the remaining estuarine habitats for juvenile fishes. As a consequence, the essential nursery function of estuarine areas may be reduced by these anthropogenic disturbances (Gibson, 1994; Able et al., 1999; Costa and Cabral, 1999; Jones et al., 2002; Whitfield and Elliott, 2002; Gilliers et al., 2006; Coates et al., 2007; Le Pape et al., 2007). Recruitment level and population size of the concerned marine species may then be dramatically affected (Peterson et al., 2000).

To monitor the quality of estuarine zones, the use of biological indicators that take into account their ecological function is becoming a widespread method (Basset and Abbiati, 2004; Coates et al., 2007). In particular, indicators based on fish communities are recognized as useful tools to assess anthropogenic impacts on estuaries (Costa and Elliott, 1991; Deegan et al., 1997; Hughes et al., 1998; Whitfield and Elliott, 2002; Borja et al., 2004; Harrison and Whitfield, 2004; Harrison and Whitfield, 2006; Breine et al., 2007). For example, to assess if transitional waters (estuaries and lagoons) within the European Union are in a good ecological status by 2015, the Water Framework Directive (WFD - Directive 2000/60/EC, Anonymous, 2000) has introduced, among others, the use of fish indicators and these tools are being developed all around Europe within this framework.

In that WFD purpose, a large data set was created in France from fish samplings carried out within 13 estuaries presenting various degrees of human activity (Gilliers et al., 2006; Amara et al., 2007). Based on this data set, our aim was to bring out and to measure the impact of anthropogenic disturbances on the nursery function of estuaries. Our approach was to make inter-estuaries comparisons of the nursery function, i.e. to compare the sampled estuaries on the basis of multispecific fish metrics that were used as proxies of the estuarine nursery function (Elliott and Dewailly, 1995). We modelled the impacts of anthropogenic disturbances, estimated thanks to contamination indices used as proxies for human pressure, on the estuarine nursery function after controlling for the variability stemming from the sampling design and some estuarine features. 


\section{Materials and methods}

\subsection{Beam trawl survey data}

In 2005 and 2006, 13 estuaries were investigated throughout France (Fig. 1), in spring and autumn, with a standardized sampling procedure (Lepage and Girardin, 2005).

Two types of beam trawl were used. One had an opening of $2.7 \mathrm{~m}$ wide and $0.6 \mathrm{~m}$ high and its net had 20-mm stretched mesh in the cod end. The other beam trawl had an opening of $1.5 \mathrm{~m}$ wide and $0.5 \mathrm{~m}$ high and a net with $10-\mathrm{mm}$ stretched mesh in the cod end. The $2.7 \mathrm{~m}$ wide beam trawl was used only in big estuaries while the $1.5 \mathrm{~m}$ wide beam trawl was used everywhere. Hauls were performed only in daylight, for about $15 \mathrm{~min}$ and at a towing speed ranging from 1.5 to 3 knots. Between 12 and 65 beam trawls were performed per estuary and per season, with a mean of 23. In total, 470 beam trawls were carried out.

For each beam trawl haul, salinity (measured using the Practical Salinity Scale) and depth were recorded at the beginning of the haul. Investigated depths range from $0.5 \mathrm{~m}$ to $20.5 \mathrm{~m}$. As investigated areas were sometimes located far upstream the estuaries (i.e. close to the freshwater environment), salinity measures could range from 0 to 36 . In each estuary, sampling points were chosen in order to sample the greatest part of potential fish habitats and to cover all the estuarine areas, from the upstream limit of tide to the open sea. Hence a wide range of salinities and depths was sampled in each of the 13 estuaries.

All fishes collected were identified, measured and counted. 71 fish species were caught and more than 15500 individuals were measured. When the number of fish from a species in a beam trawl was superior to 30 , only a representative subsample of 30 individuals was measured if size were homogeneous.

\subsection{General approach for the evaluation of the impacts of anthropogenic disturbances on the estuarine nursery function}

Figure 2 presents the general methodology adopted for this study. Specific fish metrics were used to assess the nursery function of the sampled estuaries. Similarly, indices of contamination were used to quantify the level of anthropogenic disturbances that impact the sampled estuaries. As estuaries present a high degree of intra-variability, it is difficult to standardize the sampling procedure for the acquisition of fish data (Mouillot et al., 2006). Therefore our approach was based on the idea that it was necessary to take first into account the effects of the sampling procedure on the fish metrics. Indeed, spatial gradients play a major role in estuaries, particularly the salinity gradient that depends on the relative influence of freshwater and marine water inflow (Mc Lusky, 1981; Mc Lusky and Elliott, 2004; Greenwood, 2007; Vinagre et al., 2008). For this purpose fish metrics were calculated at the beam trawl scale. Second, we tested for the impact of some estuarine features on the selected fish metrics. Only after these two main sources of variability were taken into account, the score of each estuary for the studied fish metrics was estimated. Last, the link between these scores and the level of anthropogenic disturbances was tested (Fig. 2).

\subsection{Fish metrics for the nursery function}

Fish metrics regarded as proxies for the estuarine nursery function, i.e. related to juvenile stage of marine fishes, were opted for. 


\subsubsection{Multispecific approach based on ecological guilds}

A multispecific approach based on ecological guilds was used to describe the use of estuaries as nursery grounds by marine fish species. This study focused on juveniles of fish belonging to the ecological guild called "Marine Juvenile (MJ) migrant species". This guild regroups marine fish species that use estuaries primarily as nursery grounds but usually spawn and spend much of their adult life at sea, while often returning seasonally to estuaries when adult (Elliott and Dewailly, 1995). Whether a species belongs or not to this group was determined from Elliott and Dewailly (1995), Quéro and Vayne (1997) and experts' opinions about the particular behaviour of fish species in the sampled estuaries as suggested by Elliott et al. (2007) and Franco et al. (2008). 14 of the species encountered have been considered as belonging to the guild MJ (Table 1).

To determine whether a catch from the guild $\mathrm{MJ}$ was a juvenile, a generic size at maturity was attributed to each of these 14 species (Table 1), according to Quéro and Vayne (1997) and/or to the data available on fishbase (www.fishbase.com) about the French coasts. All MJ fishes whose size was inferior to the corresponding size at maturity were regarded as juveniles (Gibson, 1994) and only juveniles from these $14 \mathrm{MJ}$ species were considered in this study. As the majority of fishes caught were juveniles, the subsampling used to measure fishes was not a problem to estimate their proportion. Thus, this study focused on the data of juveniles from the guild $\mathrm{MJ}$ that were caught in each beam trawl.

\subsubsection{Selection of fish metrics for the nursery function}

We selected $\mathrm{MJ}$ (i.e. juveniles belonging to the guild $\mathrm{MJ}$ ) densities and number of $\mathrm{MJ}$ species as fish metrics to assess the estuarine nursery function. These two fish metrics were calculated at the beam trawl scale in order to take into account the variability due to the sampling procedure.

There were not enough available data to calculate the investigated surface for each beam trawl: some hauls were not straight lines and only the starting and the ending positions of each trawl haul were known. This made the calculation of the sampled distance inaccurate for a great part of the trawl hauls. Hence, as the general sampling procedure (speed and duration of the beam trawls) was assumed to be standardized, the densities of MJ were established from numbers of $\mathrm{MJ}$ caught per beam trawl.

\subsection{Statistical methods for the analysis of fish sampling data}

The densities of $\mathrm{MJ}$ and the number of $\mathrm{MJ}$ species calculated the beam trawl scale were modelled with generalised linear models (GLMs) using R software (R Development Core Team, 2005).

\subsubsection{Modelling for marine juvenile densities}

MJ catches per trawl haul were characterised by a large number of zero: no MJ were caught in about $40 \%$ of the trawl hauls. The use of a simple linear approach to model these data is thus prohibited (Le Pape et al., 2003b). Hence, MJ densities were described with a GLM assuming a delta distribution (Stefansson, 1996). This model coupled a sub-model testing for the presence of $\mathrm{MJ}$ with a second sub-model testing for the positive densities of $\mathrm{MJ}$, i.e. the densities of $\mathrm{MJ}$ when at least one had been caught.

In the first sub-model, the presence of $\mathrm{MJ}\left(\mathrm{MJ}_{0 / 1}\right)$, used as response variable, was described with a binomial model, whose likelihood is:

Logit $\left(\mathrm{MJ}_{0 / 1}\right) \approx$ constant variable $_{1}+$ variable $_{2}+\ldots+$ variable $_{\mathrm{n}}$ 
where variable ${ }_{[1,2, \ldots, n]}$ represents the introduced descriptors that can be either continuous covariates or class factors.

The second sub-model, testing for the positive densities of $\mathrm{MJ}\left(\mathrm{MJ}_{+}\right.$, response variable), was applied to log-transformed positive density values, as positive densities comprised some very high values. The model was based on a Gaussian law, as Le Pape et al. (2003b); Nicolas et al. (2007) and preliminary analyses on the present dataset showed that it was an appropriate option to describe the lognormal distribution of the positive values. The likelihood of this model can be written as follows:

$\log \left(\mathrm{MJ}_{+}\right) \approx$ constant + variable $_{1}+$ variable $_{2}+\ldots+$ variable $_{\mathrm{n}}$

where variable $e_{[1,2, \ldots, n]}$ represents the introduced descriptors (continuous covariates or class factors).

\subsubsection{Modelling for the number of MJ species}

As numbers of MJ species are repetitive counts of species, a GLM based on a Poisson law was used to model the species richness in juvenile $\mathrm{MJ}\left(\mathrm{SR}_{\mathrm{MJ}}\right)$ in each beam trawl:

$\log \left(\mathrm{SR}_{\mathrm{MJ}}\right) \approx$ constant variable $_{1}+$ variable $_{2}+\ldots+$ variable $_{\mathrm{n}}$

Preliminary tests demonstrated that this option was appropriate to describe the distribution of the species richness in our dataset.

The statistical significance of each descriptor (described hereafter) effect was tested at the level of $5 \%$ (Chi-2 test at $5 \%$ level). The nature of their impact (positive or negative impact) on the fish metrics was determined from the sign of the corresponding coefficient(s). A graphical analysis of the residuals was carried out for each GLM in order to verify underlying hypotheses (independence and normality of the residuals of deviance).

\subsection{Descriptors of the sampling protocol, estuarine features and anthropogenic pressures}

\subsubsection{Standardization of the beam trawl survey procedure}

As sampling strategy is a key question to address when developing fish indices (Roset et al., 2007), the following descriptors were taken into account to test for the effects of the beam trawl survey procedure on the fish metrics.

\section{Type of beam trawl}

The survey procedure comprised two types of beam trawl thus introducing variability in trawl selectivity and size-dependant catchability. Thus, the beam trawl type effect was tested in models as a class descriptor (small or large).

\section{Season}

MJ species use estuaries as nursery areas seasonally (Dorel et al., 1991; Elliott and Hemingway, 2002; Vinagre et al., 2008). All considered MJ species are not necessarily present at same density on nursery grounds at each of the two sampling season and the juveniles mean size may differ from one season to the other, which might introduce bias of selectivity with the beam trawl. Thus the effects of the season on the fish metrics were also tested as a class factor (spring or autumn).

\section{Salinity and depth}

Salinity and depth are important factors structuring estuarine fish communities and influence the nursery function of estuarine habitats (Blaber and Blaber, 1980; Gibson, 1994; Le Pape 
et al., 2003b; Meng et al., 2005). Hence, their effects on the fish metrics at the beam trawl scale were analysed.

\subsubsection{Effects of estuarine features, ecoregions and size}

The studied estuaries are located in two different ecoregions: the Atlantic Ocean and the English Channel (Fig. 1). Biogeography influences the occurrence of estuarine fishes and the features of the estuarine environment (Coates et al., 2007). Thus, the effects of ecoregion on the fish metrics were tested.

The sizes of the sampled estuaries range from $0.54 \mathrm{~km}^{2}$ to almost $530 \mathrm{~km}^{2}$. The estuarine size may influence the number of MJ species (Whitfield, 1983) and had potentially to be taken into account. However, in the studied data set, the type of beam trawl was correlated with the estuarine size and this link can influence model results.

Last, the estuary was introduced as a class factor in the models, to classify the different studied estuaries with regards to their performance as nursery ground. The effect of each estuary on the fish metrics was studied using estimates calculated by $\mathrm{R}$ software with treatment contrasts. By this way, this classification takes into account the sampling protocol and the general estuarine features.

\subsubsection{Anthropogenic disturbances}

In the present study, indices of estuarine water contamination were used as proxies for human disturbances that impact the sampled estuaries.

Data of estuarine contamination

Data on the chemical contamination of coastal and estuarine waters have been collected since 1979 by the French national network of the quality of the marine environment. Seasonal measures of xenobiotics concentrations in molluscs (mussels Mytilus edulis and oysters Crassostrea gigas) are used as quantitative indicators of water contamination and values obtained from the two species are standardized (Beliaef et al., 1998; Gilliers et al., 2006). All 13 estuarine areas considered in this study correspond to sites investigated by this network. Chemicals considered in this study were five heavy metals $(\mathrm{Cd}, \mathrm{Zn}, \mathrm{Cu}, \mathrm{Hg}$ and $\mathrm{Pb}$ ) and two organic contaminants: polychlorobiphenyle (PCB) and polycyclic aromatic hydrocarbons (PAHs).

\section{Descriptors of the estuarine contamination}

For each site, median values of contamination were computed using all seasonal data over 6 years: from 2000 to 2005 . Medians were preferred to means because they are more robust with regard to outliers (Beliaef et al., 1998). A normed Principal Component Analysis (PCA) was computed in order to synthesize the data and to reduce the number of variables (contaminants, in column) used to describe the overall chemical contamination of the sites (individuals, in row).

\subsection{Disentangling between an estuary effect and contamination effect}

In the presently studied dataset, contamination is an estuary-level variable. We then tested for the relation between an estuary effect and the contamination effect. For that purpose, we studied the estuarine effect when an estuarine factor is added into the models without any contamination descriptors. We then checked for the rank correlation between estuarine effects and estuarine contamination, using a Spearman rank correlation test.

An additional analysis was done by removing the factor "estuary" from the model and adding contamination descriptors. 


\subsection{Predictions of $\mathrm{MJ}$ densities and number of species, per beam trawl}

Fitted values from GLMs were used to estimate the predicted MJ densities and the number of MJ species per trawl haul in estuaries depending on their level of contamination. These predictions were calculated for each depth and salinity on a set of the other variables that were included in the GLMs, i.e. protocol and estuarine features, depending on the variables that had a significant effect on the considered fish metric.

The fitted MJ densities resulted from the delta model, i.e. the combination of the two submodels testing respectively for the probability of $\mathrm{MJ}$ presence and the positive $\mathrm{MJ}$ densities. $10 \%$, medians and $90 \%$ quantiles were calculated with these two GLMs: the quantiles for the probability of MJ presence were calculated on 1000 trawl hauls randomly generated with the Binomial model. The quantiles for the positive log-densities of $\mathrm{MJ}$ relate to the corresponding Gaussian law.

Then, these quantiles were coupled with the following formula:

$q_{y}(M J)=q_{y}\left(M J_{0 / 1}\right) \times e^{q_{y}(\log (M J+))}$

where $q_{y}\left(M J_{0 / 1}\right)$ represents the $\mathrm{y} \%$ quantile of the probability of $\mathrm{MJ}$ presence calculated on the 1000 trawl hauls generated with the Binomial model, and $q_{y}\left(\log \left(\mathrm{MJ}_{+}\right)\right)$refers to the $y$ $\%$ quantile of the Gaussian law that corresponds to the positive log-densities model.

The fitted numbers of MJ species result from the corresponding GLM: 1000 trawl hauls were randomly generated with the Poisson model.

\section{Results}

\subsection{Effects of the sampling protocol on fish metrics for the nursery function}

\subsubsection{Type of beam trawl and sampling season}

The type of beam trawl had an important and statistically significant effect on the selected fish metrics for the estuarine nursery function. The $2.7 \mathrm{~m}$ wide beam trawl caught more fishes than the $1.5 \mathrm{~m}$ wide one (average number of $\mathrm{MJ}$ caught reached 40 and 14 respectively). Likewise, the average number of $\mathrm{MJ}$ species encountered differed from the large (2.2) to the small (0.6) beam trawl. This two levels factor (i.e. small or large beam trawl) was hence the first explicative variable introduced within GLMs.

When introduced into the GLMs after the type of beam trawl, the sampling season had a statistically significant effect on the three fish metrics: the probability of MJ presence, the positive $\mathrm{MJ}$ densities and the number of $\mathrm{MJ}$ species were greater in spring than in autumn. Consequently, the survey season (i.e. spring or autumn) was the second factor introduced within GLMs.

\subsubsection{Salinity and bathymetry}

To determine how salinity had to be taken into account in the GLMs (i.e. as a factor or as a continuous variable) preliminary data analyses were carried out. Salinity appeared to have a non-linear effect on the probability of MJ presence with an optimum around 19 to 20 (Fig. 3). The same relation was obtained for the other fish metrics (MJ positive densities and number of species). Therefore, salinity was expressed within GLMs as a four levels factor: oligohaline $(0-5)$, mesohaline (5-18), polyhaline (18-30) and euhaline $(>30)$. These salinity classes were 
adapted from the Venice System that classifies Marine Waters according to salinity (Anonymous, 1959).

Figures $4 \mathrm{a}$ and $4 \mathrm{c}$ show the negative effect of depth on $\mathrm{MJ}$ between 0.5 and $12 \mathrm{~m}$. Besides, on figure $4 \mathrm{a}$, beam trawls performed at depths superior to $12 \mathrm{~m}$ were rare (Fig. 4b). Hence, probabilities of MJ presence under $12 \mathrm{~m}$ depth were considered as non-representative, and only trawls that were performed between 0.5 and $12 \mathrm{~m}$ were tested in the GLMs. Depth was introduced as a continuous variable as it had an almost similar linear effects on the three MJ metrics in this depth range.

\subsection{Effects of general estuarine features on fish metrics for the nursery function}

When introduced in the GLMs after the type of beam trawl, the season, the salinity and the depth, the ecoregion had a statistically significant effect on the probability of MJ presence and on the number of MJ species (Table 2): in both cases, the English Channel ecoregion appeared to be more favourable to $\mathrm{MJ}$ than the Atlantic Ocean ecoregion. Hence an ecoregion factor was introduced into these GLMs.

On the contrary, the effect of estuarine size on the fish metrics was not significant when it was introduced in models after the type of beam trawl.

Hence, several descriptors of protocol (type of beam trawl, salinity, depth) and estuarine features (ecoregion) appeared to have a significant effect on the fish metrics used to describe the nursery function of estuaries. Moreover, the influence of these factors appeared to be additive and general to the studied estuaries, without crossed effects. They have been introduced in GLM models as simple descriptors (Table 2). Then, we tested for the effects of an estuary factor on the fish metrics with the following generic model:

$\mathrm{FM} \approx$ factor(beam trawl) + factor(season) + factor(salinity) + covariate(depth) + factor(ecoregion) + factor(estuary)

where FM stands for one of the three fish metrics for the estuarine nursery function. This model demonstrated significant (Table 2) differences in nursery function between the 13 studied estuaries (Table 3).

\subsection{Descriptors of contamination}

Figure 5 presents the results of the normed Principal Component Analysis computed on site $\times$ contaminants matrix of contamination median values. The first two principal components (PCA1 and PCA2) explained $78.94 \%$ of the total inertia. They discriminated heavy metals and organic pollutants. The five metallic contaminants were well correlated with each other and with first axis, whereas PCB and PAHs were well correlated with the second principal component. Thus, PCA1 clearly discriminated sites with regard to heavy metal contamination while position of sites along the second axis was linked to their organic contamination. Consequently, it was possible to compute two different indices of contamination by using coordinates of each site on PCA1 and PCA2: one for heavy metal contamination and the other for organic contamination. Last, indices of heavy metal and organic contaminations were summed to obtain a third index that estimates for overall contamination. Figure 6 presents the value of those three indices for each of the 13 sampled estuaries. These indices were separately introduced as continuous variables into the GLMs in order to test for the effects of contamination on the estuarine nursery function (Table 2).

\subsection{Impacts of anthropogenic disturbances on the nursery function of estuaries}


Estuarine effects calculated previously were shown to be negatively correlated to the level of contamination of estuaries (Table 3): nursery performances of the various estuaries decrease, from preserved to highly contaminated ones.

Then we tested for the impacts of anthropogenic disturbances on the estuarine nursery function with the following generic model, after removing the factor "estuary":

$\mathrm{FM} \approx$ factor(beam trawl) + factor(season) + factor(salinity) + covariate(depth) + factor(ecoregion) + covariate(DC)

where FM stands for one of the three fish metrics for the estuarine nursery function, and DC for one of the three descriptors of contamination for the studied estuaries (heavy metal, organic and overall contamination). The effects of each DC on each FM were tested separately, thus nine additional GLMs were realized to estimate directly the relation between nursery function and contamination.

The results of these models are summarized in table 2. They showed that the impact of environmental parameters on fish metrics was strong while contamination effects on fish metrics were less important. However, table 2 shows that contamination by heavy metals significantly decreased the positive $\mathrm{MJ}$ densities while organic contaminants had a negative effect on the probability of MJ presence and on the number of $\mathrm{MJ}$ species. Overall contamination always appeared to have a negative, statistically significant, effect on the three metrics for the estuarine nursery function.

Figure 7 presents the fitted values of the models for a theoretical estuary located in the Atlantic Ocean ecoregion and sampled in autumn with the $2.7 \mathrm{~m}$ wide beam trawl. The models were fitted for this estuary simulated as highly contaminated, i.e. such as the Seine estuary, and poorly contaminated, i.e. such as the Mont Saint Michel Bay. The nursery function of this theoretical estuary appeared to be impacted by human disturbance (simulated according to the overall contamination proxy): it sheltered lower MJ densities and less MJ species per beam trawl when highly contaminated. Moreover, the effect of human disturbance on $\mathrm{MJ}$ densities appeared highly significant as confidence intervals, embodied by $10 \%$ and $90 \%$ quantiles for the fitted densities for good or bad quality status, did not overlap each other (Fig. 7). For the fitted numbers of MJ species, quantiles calculated on the 1000 trawl hauls randomly generated with the Poisson law corresponded to discrete values comprised between 0 and 6 . They generally overlapped between the good and the bad quality status. Thus, only histograms of these 1000 trawl hauls and their mean value were represented (Fig. 7).

\section{Discussion}

\subsection{Validity and possible improvements for the modelling of fish metrics}

Many studies have used multiple regression models to analyse the relative importance of environmental variations in explaining changes in fish density (Power and Attrill, 2002, 2003; Maes et al., 2004). In the present study we used GLMs to describe the fish metrics for the estuarine nursery function. These GLMs lead to consequent unexplained variability (from 30 to $50 \%$ of the total deviance, Table 2). We first discuss the validity of these models options and their possible improvements before analysing the present results.

\subsubsection{Fish metrics accuracy}

Based on Whitfield and Elliott (2002) and Coates et al. (2007), who estimate that both are relevant and complementary, we selected $\mathrm{MJ}$ densities and number of $\mathrm{MJ}$ species as fish metrics to assess the impact of anthropogenic pressure on the estuarine nursery function.

Modelling the number of MJ individuals caught per beam trawl instead of per trawled surface unit may be discussed. Indeed, working with numbers of $\mathrm{MJ}$ per surface unit could have lead to sharper models but the surface investigated by each trawl was not available. However, as 
the duration and speed of each trawl were standardized, this approximation seemed to be realistic and did not compromise the results of this study.

\subsubsection{Residual variability linked to the sampling protocol}

Sampling protocol, which was partly described by depth and salinity, explained a large part of the variability in the descriptors of the nursery function. This result was expected: bathymetry is known to be a major descriptor of nursery grounds (Blaber and Blaber, 1980; Gibson, 1994; Riou et al., 2001; Jones et al., 2002; Le Pape et al., 2003b; Meng et al., 2005). Salinity may have direct effects on MJ, for example on their growth rate (Meng et al., 2001). It can be an important parameter when considering for the suitability of a sampled estuarine zone as a nursery ground. Salinity can also provide information on the distance from the marine environment. It is an important factor structuring estuarine fish communities (Meng et al., 2001; Lobry et al., 2003; Martino and Able, 2003; Greenwood, 2007; Martinho et al., 2007; Vinagre et al., 2008).

A possible improvement for the models concerns salinity. This descriptor was here introduced as a class factor in the models for MJ metrics. Greenwood (2007) emphasises the fact that salinity is a continuous variable in estuaries, and that considering salinity in class may not be the best way to evaluate for its effects on fish abundance and diversity. The use of generalized additive models (GAM; Hastie and Tibshirani, 1990) to fit with the response of MJ metrics to salinity (Fig. 3) could be a fruitful method to improve models but would require a significantly larger data set. However by introducing salinity as a class factor in GLMs we accounted for the greatest part of the variability due to this descriptor while realizing simple models.

The standardization of the sampling protocol could also have been improved by taking into account the sediment structure associated with each trawled areas (not available in the present data set). The sediment granulometry is indeed an important parameter to characterize nursery sites (Meng et al., 2001; Le Pape et al., 2003b). However this study focused on 14 fish species that do not have the same requirements for bottom structure; the lack of descriptor of the sediment structure in the models may have affected their precision but not their final conclusions.

\subsubsection{Residual variability linked to estuarine features}

Our approach was based on inter-estuary comparisons. Sampled estuaries range from North to South of France and belong to two biogeographic regions: the English Channel and the Atlantic Ocean (Fig.1). As taxons occurrence and density vary with latitude (Ley, 2005; Coates et al., 2007), a taxonomic approach could introduce bias linked to the biogeographical distribution of species. Hence, a multispecific approach based on ecological guilds was used to describe the overall use of estuaries made by the various fish species: species that belong to the same guild use estuaries in the same way (Simberloff and Dayan, 1991; Elliott and Dewailly, 1995; Elliott et al., 2007; Franco et al., 2008). The guild approach enables to determine robust fish metrics for the ecological functions of estuaries that can be easily extrapolated at large geographic scales (Mouillot et al., 2006; Franco et al., 2008). It allows to compare and to assess the suitability of the sampled estuaries relatively to an ecological function (here: the nursery function) regardless their latitudinal location.

Nevertheless, we considered that ecoregion was still a relevant parameter to distinguish between the studied estuaries. Biogeography influences the occurrence and the diversity of estuarine fishes (Ley, 2005; Coates et al., 2007; Franco et al., 2008). Thus, it is necessary to take into account ecoregion when comparing various estuaries in such studies (Coates et al., 2007) even though a guild approach is used (Roset et al., 2007). Moreover, ecoregion can be considered as a feature of the estuarine environment (Franco et al., 2008). The difference between the two studied ecoregions was verified in the models. 
However other estuarine features may also influence the suitability of the sampled systems as nursery grounds, such as the estuarine size, the water temperature (Le Pape et al., 2003a, 2007), the turbidity (McLusky and Elliott, 2004) and the exposure to waves of the estuarine entrance (Ley, 2005). Previous studies (Whitfield, 1983) highlighted that estuarine size may have an important effect on species richness, as bigger estuaries usually present greater exchanges with ocean and a wider range of potential habitats for the juveniles (Monaco et al., 1992; Edgar et al., 2000; Roy et al., 2001). In this study, we compared estuaries whose size ranges from $0.54 \mathrm{~km}^{2}$ to almost $530 \mathrm{~km}^{2}$. Nevertheless, in the studied data set the estuarine size was highly correlated to the type of beam trawl. Therefore estuarine size was not introduced into the models but its effects on MJ metrics were partly considered via the type of beam trawl descriptor.

The differences in water temperature between the 13 studied estuaries were partly taken into account via the ecoregion factor. Furthermore, it is unlikely (Gilliers et al., 2006) that the low performances of the most polluted estuaries as nursery grounds resulted from differences in temperature.

In any way, the relatively low number of estuaries that were here investigated (13) did not enable to consider a more complex estuarine classification. With larger datasets, and especially more sampled estuaries, possible improvements could be brought to the method with a better description of estuarine properties, including others parameters (exposure, turbidity).

\subsubsection{Uncertainty, parsimony and reliability}

To summarize, the present approach that consisted in modelling $\mathrm{MJ}$ densities and number of $\mathrm{MJ}$ species at the beam trawl scale allowed to take into account an important part of the variability for these two MJ metrics. Even though a greater part of this variability could have been explained by introducing more descriptors in the models (such as other estuarine features but also available biomass of prey; Wolff et al., 1981; Gibson, 1994; Nicolas et al., 2007), it did not affect the relevance of the results concerning the effects of contamination on the estuarine nursery function.

\subsection{Large effects of the sampling protocol on fish metrics for the nursery function of estuaries}

Previous studies emphasised the necessity for taking into account the effects of sampling protocol and estuarine features on fish metrics (Whitfield and Elliott, 2002; Mouillot et al., 2006; Roset et al., 2007). The high degree of spatial but also temporal variability that characterises estuaries (Mc Lusky, 1981) prevents from achieving completely standardized fish samplings in such areas (Mouillot et al., 2006).

This study showed that MJ metrics highly depend on the effects of the sampling procedure. Indeed, according to the models, the greatest part of the variability in these metrics was explained by descriptors linked to sampling procedure and estuarine features (Table 2). This study points the fact that it is necessary to consider fish metrics at the sampling scale when assessing the ecological status of estuaries, to understand and take into account accurately the patterns of natural variations (Roset et al., 2007).

Furthermore, working at the beam trawl scale allows for modelling on large data sets (here: 470 beam trawls). On the contrary, designing fish metrics at an estuarine scale would only allow for working on the number of sampled estuaries (here: 13), which means with few degrees of freedom and with very simple models. In these conditions, it appears complicated to develop synthetic and reliable descriptors to describe globally the sampling design of a survey. In conclusion, the important effects of the sampling protocol cannot be summarized at an estuarine scale, making the design of fish metrics for testing ecological functions and effects of anthropogenic disturbance at an estuarine scale irrelevant. This conclusion about 
the sampling protocol and the necessity to study indicators at the sampling scale and not at the water body scale is essential to assess habitat quality, as a non accurate description of the natural variability can hamper the sensitivity of fish indices to human disturbance (Roset et al., 2007).

Furthermore, working at the sampling scale will allow for testing the effects of other descriptors linked to intra-estuarine variability, such as the sediment structure or the biomass of preys, as they are probably major factors determining habitat quality (Gibson, 1994).

\subsection{Negative effects of anthropogenic disturbances on the nursery function of estuaries}

\subsubsection{Effects of contamination on the nursery function of estuaries}

Even if the specific occurring processes are unknown, as numerous factors can be involved in this response (i.e. stress, growth, mortality, food availability; Whitfield and Elliott, 2002), this study emphasised the negative link between contaminants and two MJ metrics that are considered as good proxies for the nursery function of estuaries. In previous studies, consistent differences in growth, condition indices (lipid storage) and abundance of 0-group soles among sites that present various degrees of contamination within the English Channel and the Bay of Biscay were shown: juvenile soles caught in nurseries located near harbour and close to, or within, polluted estuaries presented lower growth, lower condition indices and lower abundances (Gilliers et al., 2006; Amara et al., 2007). Sites highly impacted by anthropogenic disturbances in the form of contamination by heavy metals and organic contaminants were shown to provide low quality habitats for juvenile fishes (Whitfield and Elliott, 2002) with consequences on fish growth and survival and population renewal (Gibson, 1994). The present study emphasized the negative impact of contaminants on the nursery function of estuaries, at a larger geographic scale and on a multispecific basis, and this impact appeared important: among the 13 studied estuaries, the estuarine size is correlated with the degree of contamination (the biggest estuaries, such as the Gironde and the Seine, present the highest level of overall contamination; Fig. 6). Because of their size, large estuaries are the most favourable to marine juveniles and potentially shelter greater diversity and abundance (Meng et al., 2002; Whitfield and Elliott, 2002). As the modelling of MJ metrics revealed negative and strong correlations with overall contamination, the effect of contamination on the nursery function should be strong to overlap the estuarine size effect.

\subsubsection{Habitat loss}

In this study, contamination was considered as an approximation of the anthropogenic disturbances that impact the studied estuaries. However urban and industrial development in estuarine zones also leads to important losses of habitat for the juveniles (Lotze et al., 2006; Le Pape et al., 2007; Coleman et al., 2008). The quantity of available habitat for the juveniles is directly linked to the capacity of nursery areas (Gibson, 1994; Able et al., 1999) and the protection of these essential fish habitats is a key issue for fish population renewal and ecosystem management (Beck et al., 2001). The impacts of habitat loss on the nursery function are though difficult to quantify and to take into account in such studies based on fish samplings within estuaries. Obviously, samplings are not made in removed habitat but can only be performed in remaining surfaces. Furthermore, $\mathrm{MJ}$ densities on residual habitats are not necessarily affected by the destruction of surrounding habitats. Thus, inter-estuarine comparisons based on estuarine fish samplings do not allow evaluating for the evolution of habitat capacity with relation to habitat surface over long time periods. 
In order to evaluate for the impact of anthropogenic disturbances on the nursery function of estuaries, one of the main challenges is to determine relevant descriptors of the anthropogenic pressures impacting them. Contamination data for the sampled sites were chosen because they were directly correlated to the level of human pressure and, thus, were good proxies for it. Even if all human disturbances (habitat loss, anoxia, etc.; Peterson, 2003) are not taken into account with such proxies, this approach has shown the negative effects of anthropogenic disturbances on the nursery function of estuaries.

\subsection{Toward the design of fish indicators for the nursery function of transitional waters within the Water Framework Directive}

The present approach takes its sense from the "Driver, Pressure State, Impact, Response" (DPSIR) approach (Borja et al., 2006) developed to establish a framework for the protection of different kinds of waters, including estuarine areas, in the context of the European Water Framework directive (Basset and Abbiati, 2004). By linking metrics of good ecological status, based on fish assemblages and nursery function, to proxies of human disturbance, it allows to develop indicators for monitoring networks for the assessment of both water quality and ecological function of estuarine systems (Coates et al., 2007).

$\mathrm{MJ}$ abundance and number of species at an estuarine scale can be considered as proxies for the nursery function of estuaries (Coates et al., 2007). Both are supposed to decrease with habitat quality (Whitfield and Elliott, 2002; Coates et al., 2007) though they might not be linearly correlated to habitat deterioration (Whitfield and Elliott, 2002; Coates et al., 2007).

$\mathrm{MJ}$ densities and number of $\mathrm{MJ}$ species per beam trawl are well correlated with proxies of anthropogenic disturbances. Moreover, the differences between fitted MJ densities for a theoretical estuary highly contaminated or poorly contaminated were consequent: the $10 \%$ and $90 \%$ quantiles for these fitted densities did not overlap each over (Fig. 7). Hence, these evidences may allow determining reference norms for fitted $M J$ densities that would distinguish between the expected $\mathrm{MJ}$ densities in an estuary with relation to its ecological status (relatively to its nursery function). Thus, MJ densities may be a useful fish indicator to assess the ecological status of estuaries within the WFD. Conversely the number of MJ species per trawl haul appeared as a less robust indicator: although showing differences in fitted mean values for highly vs. poorly contaminated estuaries, confident intervals overlapped (Fig. 7).

Peterson et al. (2000) presented the need to take into account fish habitats and fish communities, and especially nursery ground, to prevent degradation in ecological function of estuaries and fish population renewal. Whitfield and Elliott (2002) pointed out the interest of monitoring estuarine health using fish studies and Franco et al. (2008) emphasised the fact that the guild approach may be useful within the WFD for transitional waters, as it may provide valuable information on the ecological status of European transitional water bodies. Moreover they showed that the nursery function is one of the main functions insured by North Sea and Atlantic European estuaries as marine fishes are one of their main components in term of ecological guilds. Thus, the state of the nursery function of estuaries might be a good proxy for their broad ecological status, and especially because juvenile fish usually stay attached to their nursery site: they generally do not migrate between estuaries and are strongly habitat specific (Amara et al., 2007), especially in low quality areas (Moles et al., 1994). Even if they may migrate between different nursery sites located within the same estuary (Vinagre et al., 2008), they remain in an environment heavily influenced by estuarine water (Le Pape et al., 2003c). Hence juvenile fishes that use estuaries as nursery grounds are likely to be impacted by anthropogenic disturbances.

As a conclusion, the simple fish metrics tested in this study may provide useful tool to monitor and assess habitat quality for juvenile fishes, as well as the general ecological status of estuaries, for the purpose of the WFD (Basset and Abbiatti, 2004). In particular, MJ 
densities appeared as really appropriate because they may allow determining relevant and robust reference norms for what would be MJ densities in estuaries in good ecological status.

\section{Acknowledgements}

This study was supported by the French national program Liteau 2, directed by the French Ministry in charge of the environment. We would like to thank all the partners involved in the collect of survey data used in this study: Eric Feunteun (Muséum National d'Histoire Naturelle, Dinard, France), Philippe Guibert and his colleagues of CREOCEAN (Nantes, France) and Sylvain Duhamel (CSLHN, Le Havre, France). We have also appreciated the friendly and fruitful collaboration with Stéphanie Pasquaud, Christine Delpech, Jacques Massé, Phillippe Boët and Didier Pont (Cemagref, France) in this framework. The authors are also grateful to the two anonymous referees for their pertinent comments on the draft version of the manuscript.

\section{References}

Able, K.W., Manderson, J.P., Studholme, A.L., 1999. Habitat quality for shallow water fishes in an urban estuary: the effects of man-made structures on growth. Marine Ecology Progress Series 187, 227-235.

Amara, R., Meziane, T., Gilliers, C., Hermel, G., Laffargue, P., 2007. Growth and condition indices in juvenile sole Solea solea measured to assess the quality of essential fish habitat. Marine Ecology Progress Series 351, 201-208.

Anonymous, 1959. The final resolution of the symposium on the classification of brackish waters. Venice 8-14th April 1958. Archivio di Oceanografia e Limnologia 11, 243-248.

Anonymous, 2000. Directive 2000/60/EC of the European Parliament and of the Council of 23 October 2000 establishing a framework for Community action in the field of water policy. Official Journal of the European Communities L327, 1-72.

Basset, A., Abbiati, M., 2004. Challenges to transitional water monitoring: ecological descriptors and scales. Aquatic Conservation: Marine and Freshwater Ecosystems 14, 1-S.

Beck, M., Heck, K., Able, K., Childers, D., Eggleston, D., Gillanders, B.M., Halpern, B., Hays, C., Hostino, K., Minello, T.J., Orth, R., Sheridan, P., Weinstein, M.P., 2001. The role of nearshore ecosystems as fish and shellfish nurseries. Bioscience 51 , 633-641.

Beliaef, B., O'Connor, T.P., Claisse, D., 1998. Comparison of chemical concentrations in mussels and oysters from the United States and France. Environmental monitoring and assessment 49, 87-95.

Blaber, S.J.M., Blaber, T.G., 1980. Factors affecting the distribution of juvenile estuarine and inshore fish. Journal of Fish Biology 17, 143-162.

Borja, A., Franco, J., Valencia, V., Bald, J., Muxika, I., Belzunce, M.J., Solaun, O., 2004. Implementation of the European Water Framework Directive from the Basque country (Northern Spain): a methodological approach. Marine Pollution Bulletin 48, 209-218.

Borja, A., Galparsoro, I., Solaun, O., Muxika, I., Tello, E.M., Uriarte, A., Valencia, V., 2006. The European water Framework Directive and the DPSIR, a methodological approach to assess the risk of failing to achieve a good ecological status. Estuarine, Coastal and Shelf Science 66, 84-96.

Breine, J.J., Maes, J., Quataert, P., Van den Bergh, E., Simoens, I., Van Thuyne, G., Belpaire, C., 2007. A fish-based assessment tool for the ecological quality of the brackish Schelde estuary in Flanders (Belgium). Hydrobiologia 575, 141-159. 
Coates, S., Waugh, A., Anwar, A., Robson, M., 2007. Efficacy of a multi-metric fish index as an analysis tool for the transitional fish component of the Water Framework Directive. Marine Pollution Bulletin 55, 225-240.

Coleman, J.M., Huh, O.K., DeWitt, B., 2008. Wetland loss in world deltas. Journal of Coastal Research 24, 1-14.

Costa, M.J., Elliott, M., 1991. Fish usage and feeding in two industrialised estuaries - the Tagus, Portugal, and the Forth, Scotland. In: Elliott M. and Ducrotoy J-P. (eds), Estuaries and coasts: Spatial and temporal intercomparisons. Olsen \& Olsen, Fredensborg, Denmark, 289-297.

Costa, M.J., Cabral, H.N., 1999. Changes in the Tagus nursery function for commercial fish species: some perspective for management. Aquatic Ecology 33, 287-292.

Costanza, R., D'Arge, R., De Groot, R., Farber, S., Grasso, M., Hannon, B., Limburg, K., Naeem, S., O'Neill, R.V., Paruelo, J., Raskin, R.G., Sutton, P., Van Den Belt, M., 1997. The value of the world's ecosystem services and natural capital. Nature 387, 253-260.

Deegan, L.A., Finn, J.T., Ayvazian, S.G., Ryder-Kieffer, C.A., Buonaccorsi, J., 1997. Development and validation of an estuarine biotic integrity index. Estuaries 20, 601-617.

Dorel, D., Koutsikopoulos, C., Désaunay, Y., Marchand, J., 1991. Seasonal distribution of young common sole (Solea solea L.) in the nursery ground of the bay of Vilaine (Northern Bay of Biscay). Netherlands Journal of Sea Research 27, 297-306.

Edgar, G.J., Barrett, N.S., Graddon, D.J., Last, P.R., 2000. The conservation significance of estuaries: a classification of Tasmanian estuaries using ecological, physical and demographic attributes as a case study. Biological Conservation 92, 383-397.

Elliott, M., Dewailly, F., 1995. The Structure and Components of European Estuarine Fish Assemblages. Netherlands Journal of Aquatic Ecology 29, 397-417.

Elliott, M., Hemingway, K.L., 2002. Fishes in Estuaries. Blackwell Science, Oxford. 636 pp.

Elliott, M., Whitfield, A.K., Potter, I.C., Blaber, S.J.M., Cyrus, D.P., Nordlie, F.G., Harrison, T.D., 2007. The guild approach to categorizing estuarine fish assemblages: a global review. Fish and Fisheries 8, 241-268.

Franco, A., Elliott, M., Franzoi, P., Torricelli, P., 2008. Life strategies of fishes in European estuaries : the functional guild approach. Marine Ecology Progress Series 354, 219-228.

Gibson, R.N., 1994. Impact of habitat quality and quantity on the recruitment of juvenile flatfishes. Netherlands Journal of Sea Research 32, 191-206.

Gilliers, C., Le Pape, O., Désaunay, Y., Morin, J., Guérault, D., Amara, R., 2006. Are Growth and density quantitative indicators of essential fish habitat quality? An application to the common sole Solea solea nursery grounds. Estuarine, Coastal and Shelf Science 69, 96106.

Greenwood, M.F.D., 2007. Nekton Community Change Along Estuarine Salinity Gradients: Can Salinity Zones be Defined? Estuaries and Coasts 30, 537-542.

Harrison, T.D., Whitfield, A.K., 2004. A multi-metric fish index to assess the environmental condition of estuaries. Journal of Fish Biology 65, 683-710.

Harrison, T.D., Whitfield, A.K., 2006. Application of a multimetric fish index to assess the environmental condition of South African estuaries. Estuaries and Coasts 29, 1108-1120.

Hastie, T. J., Tibshirani, R. J., 1990. Generalized Additive Models. Chapman \& Hall, London. $335 \mathrm{pp}$.

Hughes, R.M., Kaufmann, P.R., Herlihy, A.T., Kincaid, T.M., Reynolds, L., Larsen, D.P., 1998. A process for developing and evaluating indices of fish assemblage integrity. Canadian Journal of Fisheries and Aquatic Sciences 55, 1618-1631.

Jones, R.F., Baltz, D.M., Allen, R.L., 2002. Patterns of resource use by fishes and macroinvertebrates in Barataria Bay, Louisiana. Marine Ecology Progress Series 237, 271289.

Le Pape, O., Holley, J., Guérault, D., Désaunay, Y., 2003a. Coastal and estuarine essential fish habitat quality. Estimations based on the size of juvenile common sole (Solea solea, L.). Estuarine, Coastal and Shelf Science 58, 793-803.

Le Pape, O., Chauvet, F., Mahévas, S., Lazure, P., Guérault, D., Désaunay, Y., 2003b. Quantitative description of habitat suitability for the juvenile common sole (Solea solea, L.) in 
the Bay of Biscay (France) and the contribution of different habitats to the adult population. Journal of Sea Research 50, 139-149.

Le Pape, O., Chauvet, F., Désaunay, Y., Guérault, D., 2003c. Relationship between interannual variations of the river plume and the extent of nursery grounds for the common sole (Solea solea, L.) in Vilaine Bay. Effects on recruitment variability. Journal of Sea Research 50, 177-185.

Le Pape, O., Gilliers, C., Riou, P., Morin, J., Amara, R., 2007. Convergent signs of degradation of both the capacity and the quality of an essential fish habitat: synthesis on the Seine estuary (France), a highly anthropised estuary of which flatfish nursery function is altered. Hydrobiologia 588, 225-229.

Lepage, M., Girardin, M., 2005. Inventaire Poisson dans les eaux de transition - Protocole d'échantillonnage pour les Districts de la façade Atlantique et Manche. Report for the French Ministry in charge of the Environment, Cemagref, Bordeaux, France, $28 \mathrm{pp}$.

Ley, J.A., 2005. Linking fish assemblages and attributes of mangrove estuaries in tropical Australia: criteria for regional marine reserves. Marine Ecology Progress Series 305, 41-57.

Lobry, J., Mourand, L., Rochard, E., Elie, P., 2003. Structure of the Gironde estuarine fish assemblages: a comparison of European estuaries perspective. Aquatic Living Resources $16,47-58$.

Lotze, H.K., Lenihan, H.S., Bourque, B.J., Bradbury, R.H., Cooke, R.G., Kay, M.C., Kidwell, S.M., Kirby, M.X., Peterson, C.H., Jackson, J.B.C., 2006. Depletion, Degradation, and Recovery Potential of Estuaries and Coastal Seas. Science 312, 1806-1809.

Maes, J., Van Damme, S., Meire, P., Ollevier, F., 2004. Statistical modelling of seasonal and environmental influences on the population dynamics of an estuarine fish community. Marine Biology 145, 1033-1042.

Martino, E.J., Able, K.W., 2003. Fish assemblages across the marine to low salinity transition zone of a temperate estuary. Estuarine, Coastal and Shelf Science 56, 969-987.

Martinho, F., Leitao, R., Viegas, I., Dolbeth, M., Neto, J.M., Cabral, H.N., Pardal, M.A., 2007. The influence of an extreme drought event in the fish community of a southern Europe temperate estuary. Estuarine, Coastal and Shelf Science 75, 537-546.

Mc Lusky, D.S., 1981. The estuarine ecosystem. Wiley, New York, 150 pp.

Mc Lusky, D.S., Elliott, M., 2004. The estuarine ecosystem - Ecology, threats and management. $3^{\text {rd }}$ ed. New York, Oxford University Press, 214 pp.

Meng, L., Powell, J.C., Taplin, B., 2001. Using winter flounder growth rate to assess habitat quality across anthropogenic gradient in Narragansett Bay, Rhode Island. Estuaries 24, 576584.

Meng, L., Orphanides, C.D., Powell, J.C., 2002. Use of a Fish Index to Assess Habitat Quality in Narragansett Bay, Rhode Island. Transactions of the American Fisheries Society 131, 731-742.

Meng, L., Cicchetti, G., Raciti, S., 2005. Relationships between Juvenile Winter Flounder and Multiple-Scale Habitat Variation in Narragansett Bay, Rhode Island. Transactions of the American Fisheries Society 134, 1509-1519.

Moles, A., Rice, S., Norcross, B.L., 1994. Non-avoidance of hydrocarbon laden sediments by juvenile flatfishes. Netherlands Journal of Sea Research 32, 361-367.

Monaco, M.E., Lowery, T.A., Emmet, R.L., 1992. Assemblages of U.S. West Coast estuaries based on the distribution of fishes. Journal of Biogeography 19, 251-267.

Mouillot, D., Spatharis, S., Reizopoulou, S., Laugier, T., Sabetta, L., Basset, A., Do Chi, T., 2006. Alternatives to taxonomic-based approaches to assess changes in transitional water communities. Aquatic Conservation: Marine and Freshwater Ecosystems 16, 469-482.

Nicolas, D., Le Loc'h, F., Desaunay, Y., Hamon, D., Blanchet, A., Le Pape, O., 2007. Relationships between benthic macrofauna and habitat suitability for juvenile common sole (Solea solea, L.) in the Vilaine estuary (Bay of Biscay, France) nursery ground. Estuarine, Coastal and Shelf Science 73, 639-650.

Peterson, M.S., 2003. A Conceptual View of Environment-Habitat-Production Linkages in Tidal River Estuaries. Reviews in Fisheries Science 11, 291-313. 
Peterson, C.H., Summerson, H.C., Thomson, E., Lenihan, H.S., Grabowski, J., Manning, L., Micheli, F., Johnson, G., 2000. Synthesis of linkages between benthic and fish communities as key to protecting essential fish habitat. Bulletin of Marine Science 66, 759-774.

Post, J.C., Lundin, C.G., 1996. Guidelines for integrated coastal zone management. Environmentally Sustainable Development Studies and Monographs Series $N^{\circ}$, World Bank, Washington, D.C. 16 pp.

Power, M., Attrill, M.J., 2002. Factors affecting long-term trends in the estuarine abundance of pogge (Agonus cataphractus). Estuarine, Coastal and Shelf Science 54, 941-949.

Power, M., Attrill, M.J., 2003. Long-term trends in the estuarine abundance of Nilsson's Pipefish (Syngnathus rostellatus). Estuarine, Coastal and Shelf Science 57, 325-333.

Quéro, J.C., Vayne, J.J., 1997. Les poissons de mer des pêches françaises. Ifremer, éditions Delachaux et Niestlé, 304 pp.

R Development Core Team, 2005. R: A language and environment for statistical computing. R Foundation for Statistical Computing, Vienna, Austria, ISBN 3-900051-07-

0, URL http:www.R-project.org.

Riou, P., Le Pape, O., Rogers, S.I., 2001. Relative contributions of different sole and plaice nurseries to the adult population in the Eastern Channel: application of a combined method using generalized linear models and a geographic information system. Aquatic Living Resources 14, 125-135.

Roset, N., Grenouillet, G., Goffaux, D., Pont, D., Kestemont, P., 2007. A review of existing fish assemblage indicators and methodologies. Fisheries Management and Ecology 14, 393405.

Roy, P.S., Williams, R.J., Jones, A.R., Yassini, I., Gibbs, P.J., Coates, B., West, R.J., Scanes, P.R., Hudson, J.P., Nichol, S., 2001. Structure and Function of South-East Australian Estuaries. Estuarine, Coastal and Shelf Sciences 53, 351-384.

Stefansson, G., 1996. Analysis of groundfish survey abundance data: combining the GLM and delta approaches. ICES Journal of Marine Science 53, 577-588.

Simberloff, D., Dayan, T., 1991. The Guild Concept and the Structure of Ecological Communities. Annual Review of Ecology and Systematics 22, 115-143.

Vinagre, C., Salgado, J., Costa, M.J., Cabral, H.N., 2008. Nursery fidelity, food web interactions and primary sources of nutrition of the juveniles of Solea solea and $S$. senegalensis in the Tagus estuary (Portugal): A stable isotope approach. Estuarine, Coastal and Shelf Science 76, 255-264.

Whitfield, A.K., 1983. Factors influencing the utilization of Southern African estuaries by fishes. South African Journal of Science 79, 362-365.

Whitfield, A.K., Elliott, M., 2002. Fishes as indicators of environmental and ecological changes within estuaries: a review of progress and some suggestions for the future. Journal of Fish Biology 61, 229-250.

Whittaker, R.H., 1975. Communities and Ecosystems, 2nd edit. Macmillan, Londres. In: Raven, P.H., Johnson, G.B., Losos, J.B., Singer, S.R., 2007. Biologie, edit. De Boeck, 1250 pp.

Wolff, W.J., Mandos, M.A., Sandee, A.J.J., 1981. Tidal migration of plaice and flounders as a feeding strategy. In Jones, N.V., Wolff, W.J., (Ed.), 1981. Feeding and survival strategies of estuarine organisms. Marine Science 15, 159-171. 


\section{Tables}

Table 1: Marine juvenile migrant species encountered and their generic size at maturity

Table 2: Results of the generalized linear models realized on Marine Juveniles for the probability of presence $\left(\mathrm{MJ}_{0 / 1}\right)$, the positive densities $\left(\mathrm{MJ}_{+}\right)$and the number of species $\left(\mathrm{SR}_{\mathrm{MJ}}\right)$. Residual degrees of freedom (Resid. Dof), residual deviance (Resid. Dev), statistical significance (Sign.) and signs of the slopes (Slope) are mentioned. NS: non-significant; NA: non-applicable; *: p-value $\leq 5 \%$; **: $\leq 1 \%$; ${ }^{* * *}: \leq 0.1 \%$.

Table 3: Estuarine effects, i.e. parameters of the models calculated with treatment contrasts, and results of Spearman rank correlation test (Spearman $\rho$ ) between the estuarine effect on the three fish metrics (probability of presence $\left(\mathrm{MJ}_{0 / 1}\right)$, positive densities $\left(\mathrm{MJ}_{+}\right)$and number of species $\left.\left(\mathrm{SR}_{\mathrm{MJ}}\right)\right)$ and the level of overall contamination of estuaries. ${ }^{*}$ : $p$-value $\leq 5 \%$; ${ }^{*}: \leq 1$ $\% ; * \star *: \leq 0.1 \%$. 


\begin{tabular}{lllc}
\hline Scientific name & Common name & Family & $\begin{array}{c}\text { Generic size at } \\
\text { maturity (mm) }\end{array}$ \\
\hline Argyrosomus regius & Meagre & Sciaenidae & 800 \\
Clupea harengus & Atlantic herring & Clupeidae & 260 \\
Dicentrarchus labrax & European seabass & Moronidae & 300 \\
Dicentrarchus punctatus & Spotted seabass & Moronidae & 300 \\
Limanda limanda & Dab & Pleuronectidae & 240 \\
Merlangius merlangus & Whiting & Gadidae & 220 \\
Pleuronectes platessa & European plaice & Pleuronectidae & 300 \\
Psetta maxima & Turbot & Scophthalmidae & 270 \\
Raja clavata & Thornback ray & Rajidae & 800 \\
Scophthalmus rhombus & Brill & Scophthalmidae & 250 \\
Solea senegalensis & Senegalese sole & Soleidae & 260 \\
Solea solea & Common sole & Soleidae & 260 \\
Chelidonichthys lucernus & Tub gurnard & Triglidae & 185 \\
Trisopterus luscus & Pouting & Gadidae & 200 \\
\hline
\end{tabular}




\begin{tabular}{|c|c|c|c|c|c|}
\hline & & $\begin{array}{l}\text { Resid. } \\
\text { DoF }\end{array}$ & $\begin{array}{l}\text { Resid. } \\
\text { Dev }\end{array}$ & Sign. & Slope \\
\hline \multicolumn{6}{|l|}{ Binomial Model (0/1 MJ) } \\
\hline & NULL & 469 & 623,6 & & \\
\hline \\
\hline \multicolumn{2}{|l|}{ + Depth + Ecoregion } & 462 & 370,8 & & \\
\hline \multirow{4}{*}{$\begin{array}{c}\text { additional descriptors, tested } \\
\text { separately: }\end{array}$} & + Estuary & 451 & 333,0 & $* * *$ & NA \\
\hline & + Metals & & & NS & \\
\hline & + Organic & 461 & 366,5 & * & - \\
\hline & $\begin{array}{l}+ \text { Overall } \\
\text { contamination }\end{array}$ & 461 & 365,2 & * & - \\
\hline \multicolumn{6}{|l|}{ Positive log-values Model $\left(\mathrm{MJ}_{+}\right)$} \\
\hline & NULL & 291 & 636,3 & & \\
\hline \multicolumn{6}{|l|}{$\mathrm{MJ}_{+} \sim$ Trawl + Season + Salinity } \\
\hline \multicolumn{2}{|l|}{ + Depth } & 285 & 466,5 & & \\
\hline \multirow{4}{*}{$\begin{array}{c}\text { additional descriptors, tested } \\
\text { separately: }\end{array}$} & + Estuary & 274 & 427,1 & ** & NA \\
\hline & + Metals & 284 & 435,8 & $* * *$ & - \\
\hline & $\begin{array}{l}\text { + Organic } \\
\text { + Overall }\end{array}$ & & & NS & \\
\hline & contamination & 284 & 450,5 & ** & - \\
\hline \multicolumn{6}{|l|}{ Poisson Model } \\
\hline & NULL & 469 & 664,1 & & \\
\hline \multicolumn{2}{|l|}{$\begin{array}{l}\mathrm{SR}_{\mathrm{MJ}} \sim \mathrm{Trawl}+\text { Season + Salinity } \\
\text { + Depth + Ecoregion }\end{array}$} & 462 & 350,6 & & \\
\hline \multirow{3}{*}{$\begin{array}{l}\text { additional descriptors, tested } \\
\text { separately: }\end{array}$} & $\begin{array}{l}+ \text { Estuary } \\
+ \text { Metals }\end{array}$ & 451 & 293,5 & NS & NA \\
\hline & + Organic & 461 & 335,3 & $* * *$ & - \\
\hline & $\begin{array}{l}\text { + Overall } \\
\text { contamination }\end{array}$ & 461 & 340,2 & ** & - \\
\hline
\end{tabular}




\begin{tabular}{lrrr} 
Estuarine effect on: & $\mathrm{MJ}_{0 / 1}$ & $\mathrm{MJ}_{+}$ & $\mathrm{SR}_{\mathrm{MJ}}$ \\
\hline Adour & 0 & 0 & 0 \\
Authie & 0,73 & 0,85 & 0,20 \\
Bay of Veys & 1,12 & 0,94 & 0,65 \\
Bidassoa & $-2,03$ & $-0,38$ & $-0,78$ \\
Canche & 0,00 & 0,64 & $-0,24$ \\
Charente & $-0,84$ & 0,17 & $-0,42$ \\
Mont Saint Michel Bay & 1,26 & 1,25 & 0,54 \\
Gironde & $-16,02$ & $-0,58$ & $-16,05$ \\
Loire & $-16,13$ & 0,70 & $-16,02$ \\
Orne & 0,94 & 0,56 & 0,16 \\
Seine & $-15,78$ & $\mathrm{NA}$ & $-15,96$ \\
Seudre & $-3,50$ & $-0,50$ & $-2,56$ \\
Somme & $\mathrm{NA}$ & 1,00 & $\mathrm{NA}$ \\
\hline Spearman rank correlation test with levels of overall \\
contamination: \\
Spearman $\rho$ & $-0,71$ & $-0,74$ & $-0,71$ \\
p-value & * & $* *$ \\
\hline
\end{tabular}




\section{Figures}

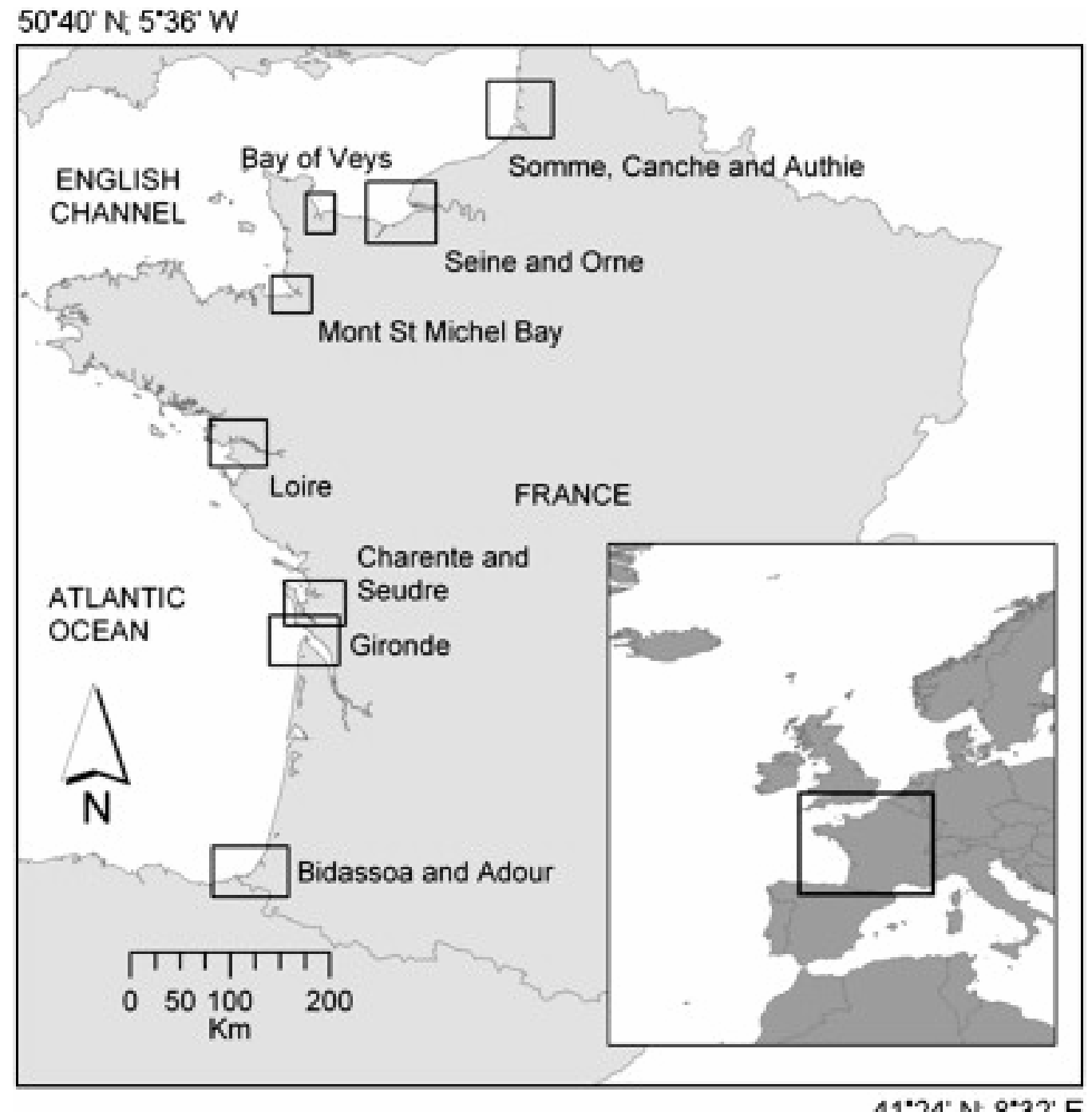

Fig. 1. Location of the 13 French estuarine areas studied in the present work. In lower left corner: general location of the study area. 


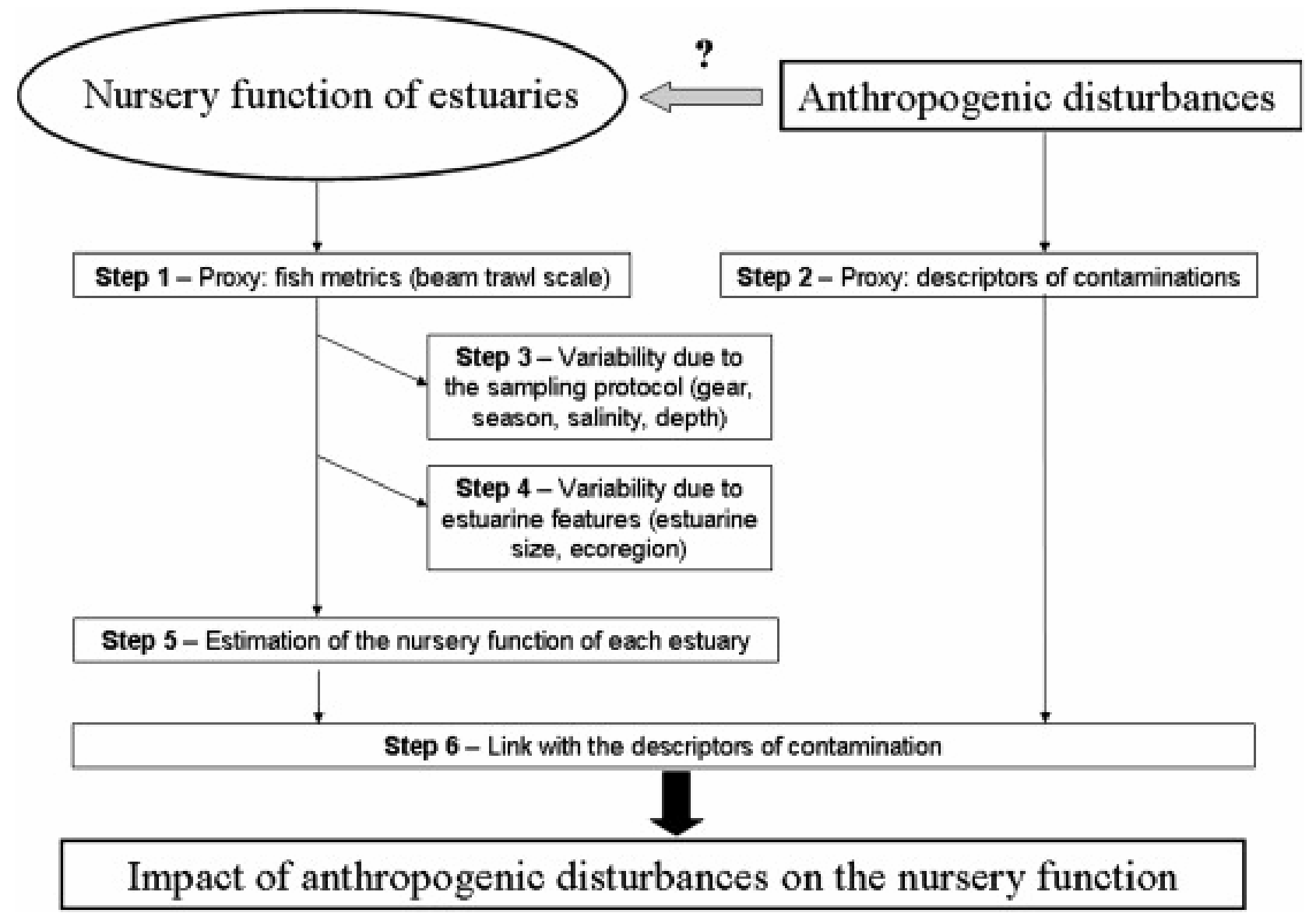

Fig. 2. General methodology for testing the impacts of anthropogenic disturbances on the estuarine nursery function, from fish metrics calculated with beam trawl survey data 


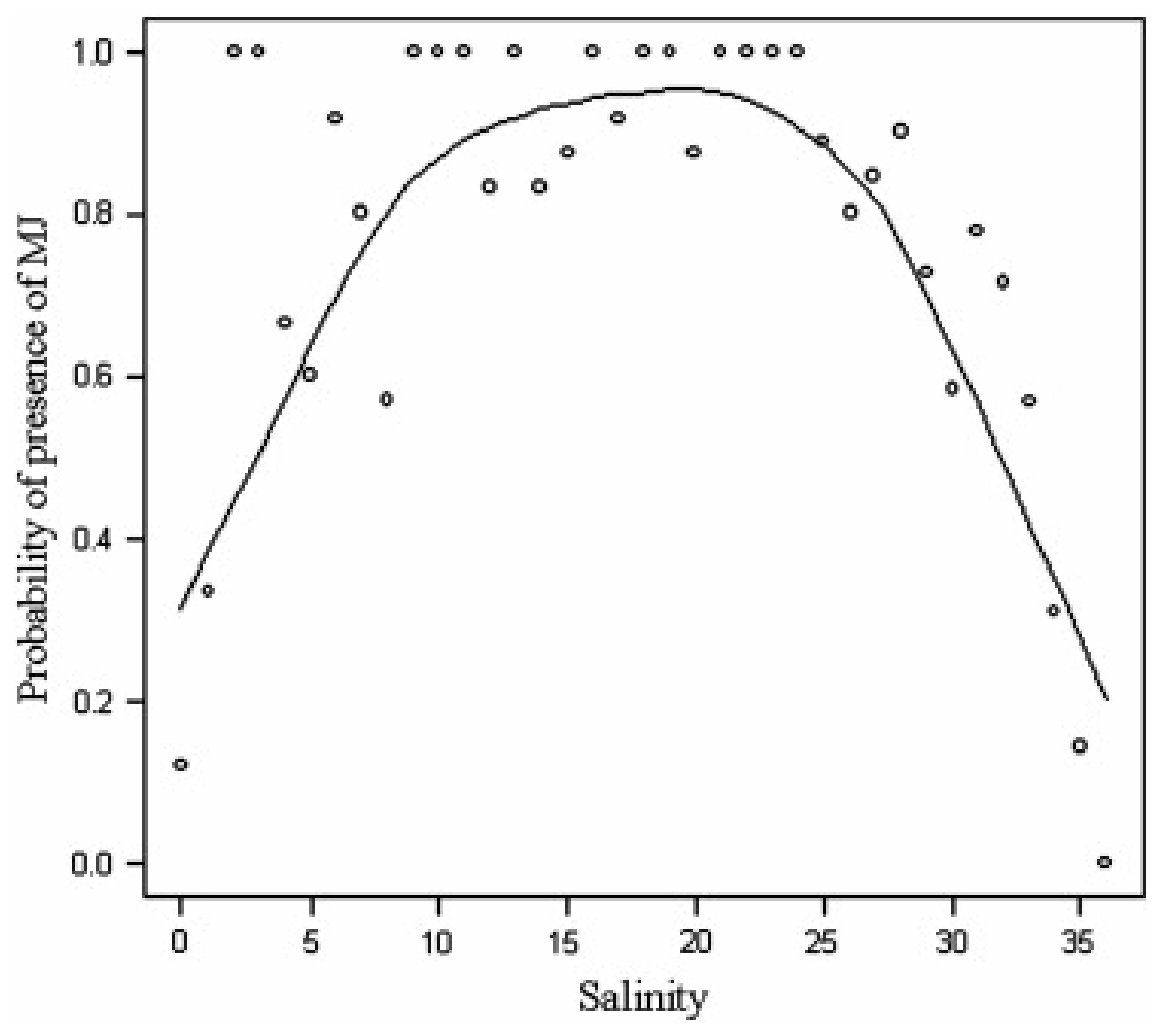

Fig. 3. Probability of MJ presence by discrete salinity values
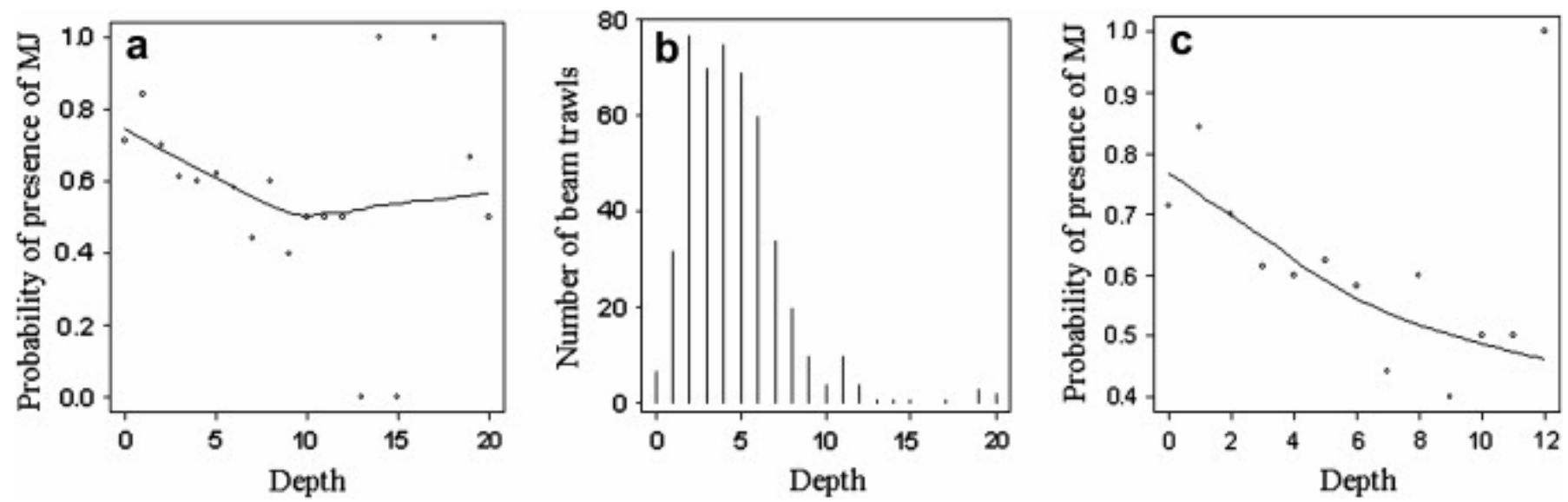

Fig. 4. Probability of MJ presence $(a, c)$ and number of beam trawls (b) per discrete depth values 


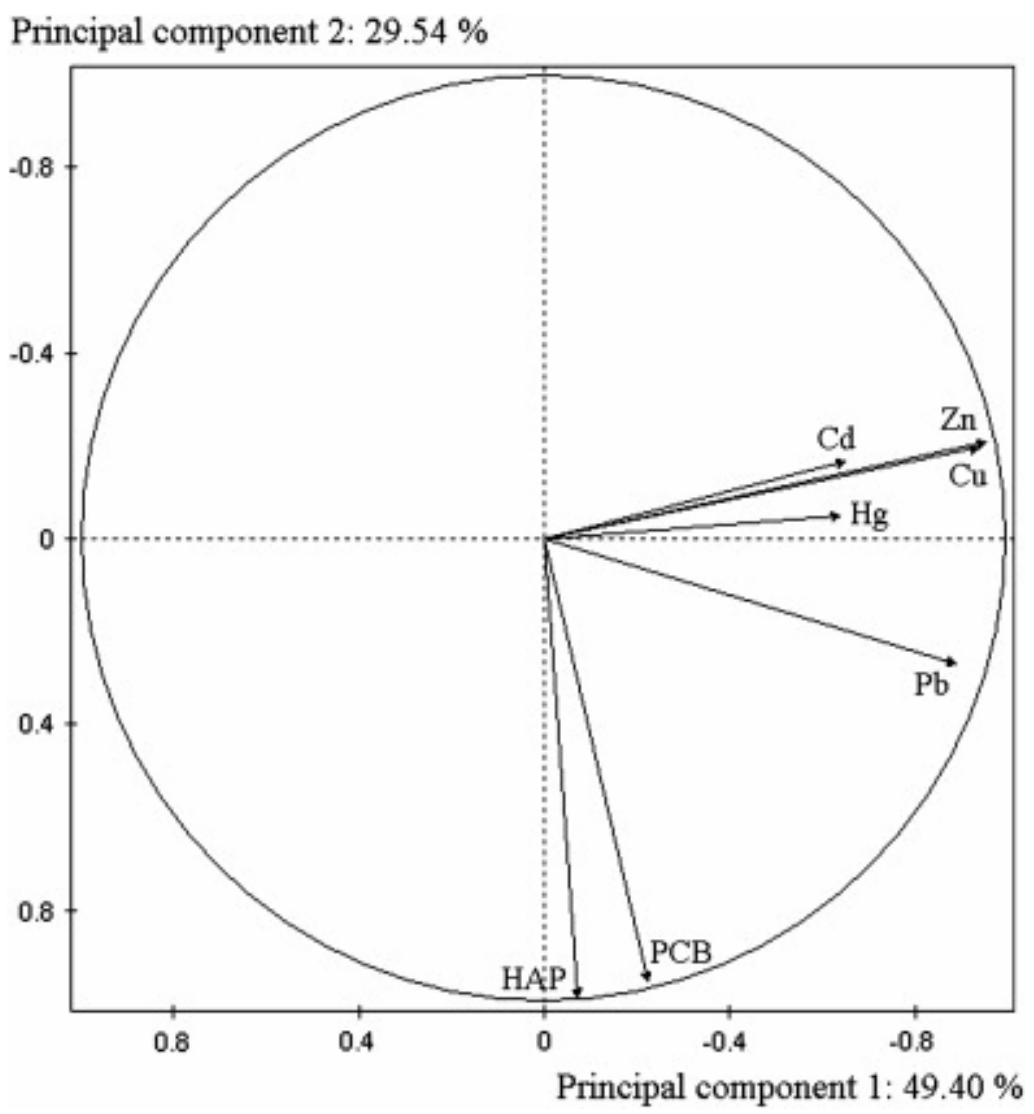

Fig. 5. Correlation circle of the PCA computed on quantitative values of the 13 sampled estuaries' contamination by five heavy metals $(\mathrm{Cu}, \mathrm{Cd}, \mathrm{Zn}, \mathrm{Hg}, \mathrm{Pb})$ and two organic xenobiotics (PCB and PAHs)

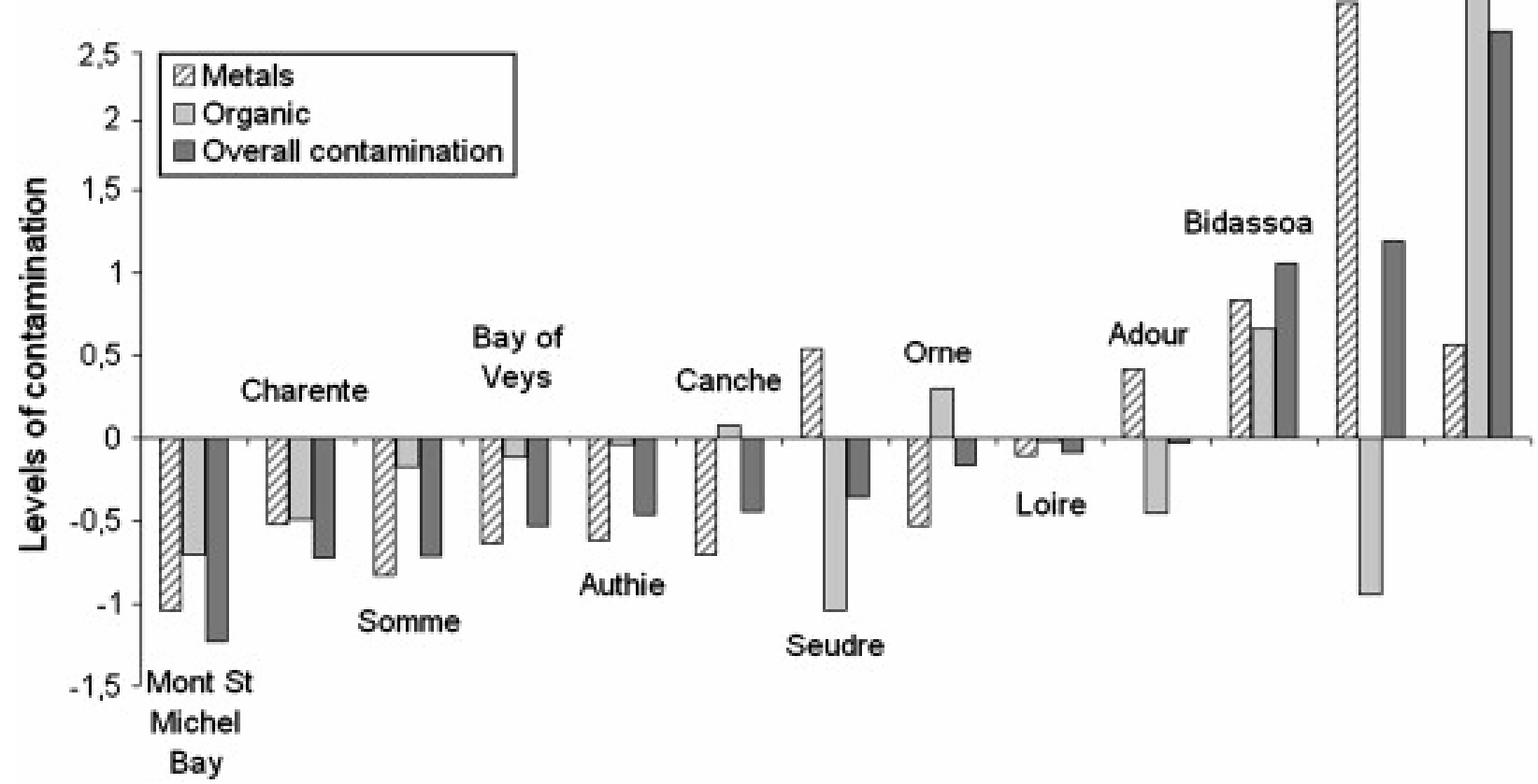

Fig. 6. Heavy metals, organic and overall contamination indices for the 13 studied estuaries classified along the horizontal axis according to an ascending level of overall contamination 


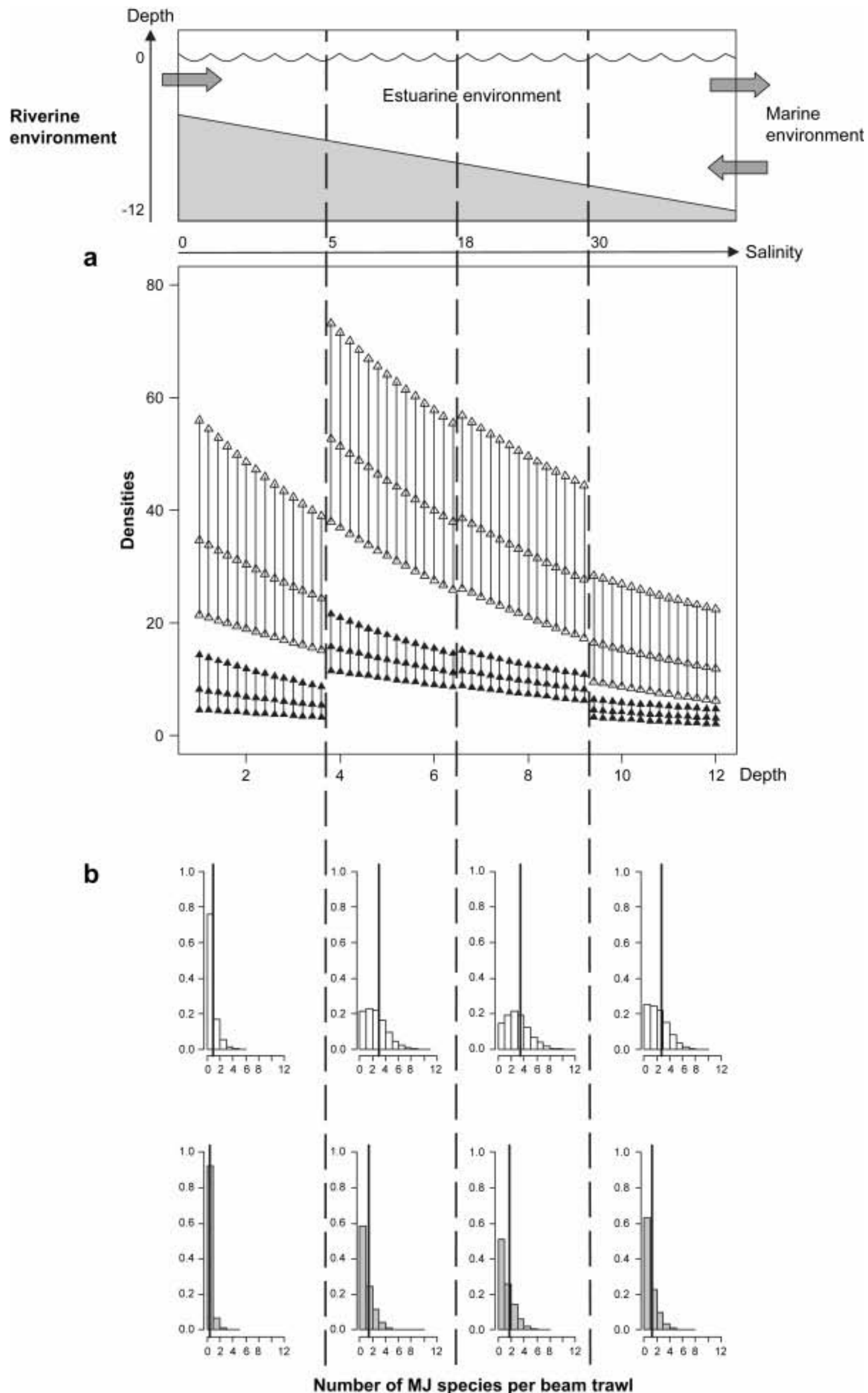


Fig. 7. Simulated MJ metrics for a virtual estuary located in the Atlantic Ocean ecoregion, sampled in autumn with the $2.7 \mathrm{~m}$ wide beam trawl, for high (dark) and low (light) overall contamination: (a) $\mathrm{MJ}$ densities (number of $\mathrm{MJ}$ per beam trawl resulting from the delta model); triangles correspond to $10 \%, 50 \%$ and $90 \%$ quantiles; (b) number of $\mathrm{MJ}$ species per beam trawl; black lines correspond to mean values for 1000 iterations of the Poisson model. 